\title{
Significant Enhancement of Mechanical and Thermal Properties of Thermoplastic Polyester Elastomer by Polymer Blending and Nanoinclusion
}

\author{
Manwar Hussain, ${ }^{1}$ Young Hui Ko, ${ }^{2}$ and Yong Ho Choa ${ }^{1}$ \\ ${ }^{1}$ Dept. of Chemical and Materials Engineering, Hanyang University, Ansan City 425-386, Republic of Korea \\ ${ }^{2}$ Shinil Chemical Ind. Ltd., 675-4 Seonggok-dong, Ansan City, Gyeonggi-do 425-386, Republic of Korea \\ Correspondence should be addressed to Yong Ho Choa; choa15@hanyang.ac.kr
}

Received 8 December 2015; Revised 15 February 2016; Accepted 22 February 2016

Academic Editor: Antonios Kelarakis

Copyright (C) 2016 Manwar Hussain et al. This is an open access article distributed under the Creative Commons Attribution License, which permits unrestricted use, distribution, and reproduction in any medium, provided the original work is properly cited.

\begin{abstract}
Thermoplastic elastomer composites and nanocomposites were fabricated via melt processing technique by blending thermoplastic elastomer (TPEE) with poly(butylene terephthalate) (PBT) thermoplastic and also by adding small amount of organo modified nanoclay and/or polytetrafluoroethylene (PTFE). We study the effect of polymer blending on the mechanical and thermal properties of TPEE blends with and without nanoparticle additions. Significant improvement was observed by blending only TPEE and virgin PBT polymers. With a small amount $(0.5 \mathrm{wt} . \%)$ of nanoclay or PTFE particles added to the TPEE composite, there was further improvement in both the mechanical and thermal properties. To study mechanical properties, flexural strength (FS), flexural modulus (FM), tensile strength (TS), and tensile elongation (TE) were all investigated. Thermogravimetric analysis (TGA) and differential scanning calorimetry (DSC) were used to analyze the thermal properties, including the heat distortion temperature (HDT), of the composites. Scanning electron microscopy (SEM) was used to observe the polymer fracture surface morphology. The dispersion of the clay and PTFE nanoparticles was confirmed by transmission electron microscopy (TEM) analysis. This material is proposed for use as a baffle plate in the automotive industry, where both high HDT and high modulus are essential.
\end{abstract}

\section{Introduction}

There is currently a significant amount of research on the addition or blending of polymeric materials for the development of new polymeric materials with desired mechanical and thermal properties. Choosing a polymer suitable for blending at the molecular level is an important task for scientists. In most cases, researchers produce polymers with poor properties due to inadequate blending and mixing at the molecular level. The properties of mixed blends or multiphase polymeric systems are determined not only by the properties of the component polymers but also by the final morphology $[1,2]$. Compatibilizers are often used to bond the different polymeric materials [3-5]. Among the compatibilizers used, maleic anhydride is the most prevalent, since it provides good interfacial bonding and improved mechanical properties $[6$, 7].
Hytrel, Skypel, and Kopel are all registered trademarks for thermoplastic polyester elastomers (TPEEs). These are important thermoplastic elastomers because of their excellent mechanical, physical, and processing characteristics. TPEEs, when combined with other polyesters, offer a unique combination of mechanical, physical, and chemical properties which qualifies them for demanding applications [8, 9]. TPEEs also show good resistance to tear, impact, abrasion, creep, and excellent oil resistance and are thus used for a wide variety of automotive parts such as gears, sprockets, hoses, and tubing [10-12].

The various grades of TPEEs also exhibit a wide range of flexibility/stiffness and processing capabilities. TPEEs combine the chemical and material properties of chemically cross-linked elastomers with those of engineered plastics, which are often easier and more affordable to manufacture. These materials consist of multiple domains, instead of 
the single domain found in polyesters, which are commonly referred to as "hard" and "soft" blocks. The "soft" blocks are responsible for the elastomeric characteristics of these materials, whereas the "hard" blocks contain a fixed chain network responsible for the reversibility of the thermal network structure in such materials.

To be useful for automotive applications, the most important material property is the ability to withstand repeated thermal cycles that may involve high temperatures while potentially requiring a significant amount of flexibility and resistance to fatigue. In addition, these materials must possess excellent chemical resistance, toughness, and color stability in order to be effectively applied in practical applications. It is possible to produce an effective TPEE material that fits these stringent criteria by carefully blending thermoplastics with nanoparticles.

Nanocomposites consisting of a polymer matrix and organo clays have attracted great interest because of the significant improvements in physical, mechanical, and thermal properties that can be achieved when compared with their unmodified polymers like nylon [13, 14], polyimide [15], polystyrene [16], and polyolefin [17, 18]. There have been few studies on polymer blends using nanoclay. Using nanoclays as an additive, only PS/PMMA, PS/PP, PA6/EPR, PPO/PA6, and $\mathrm{PPO} / \mathrm{PS}$ systems have been studied so far [19-22]. Polymer blending using TPPE and polyester has not been extensively studied.

This study is intended to assist design engineers in the successful and efficient design of parts made from TPEE thermoplastic polyester elastomers and their nanocomposite blends. Many of the same design considerations that apply to metals and other engineering materials apply to TPEE and TPEE blends. However, because all engineering materials are affected to some extent by temperature, moisture, and other environmental conditions, it is necessary to determine the possible extremes which may occur during operation and design within these constraints.

In this study, we have chosen low cost TPEEs, as well as some blends made with PBT polyester, due to their properties. The addition of nanosized clay particles to the various polymers resulted in improved mechanical properties [23]. However, the ability to disperse nanoclay in the TPEE polymers and exfoliate is a challenge. PTFE is generally used to improve the abrasion resistance of the polymeric materials; however, the improvement on mechanical and thermal property is not reported so far. We successfully added a small amount of homogeneously dispersed clay material and PTFE molecules in nanolevel which significantly enhanced both the mechanical and thermal properties.

\section{Materials}

Skypel G155D from SK chemicals, Republic of Korea, was used as the base TPEE matrix. PBT-1200-211M from Chang Chun Chemicals, Taiwan, was purchased to blend with the TPE. The PBT was dried at $80^{\circ} \mathrm{C}$ for $4 \mathrm{hrs}$ prior to blending with TPEE. PETG, KN100 grade, from SK chemicals, was also used for blending with the TPEE matrix. Maleic anhydride from Cray Valley Chemical Co., Ltd. was used as a compatibilizer. Low molecular weight PTFE with particle sizes from 2 to 3 microns was purchased from Suzhou Norshine Performance Materials Co., Ltd., China, and used as is. Antioxidant Irgafos 168 and 1010 was purchased from Ciba Chemicals. Organically modified clay $93 \mathrm{~A}$ was purchased from Southern Clay, USA. A twin extruder with L/D 45 TK-45, Republic of Korea, was used for melt mixing and making pellets. The chemical structures for TPEE, PBT, PETG, and organo clay are shown in Figures $1(\mathrm{a}), 1(\mathrm{~b}), 1(\mathrm{c})$, and $1(\mathrm{~d})$, respectively. All results were compared to Hytrel 7246 purchased from DuPont and used as is.

\section{Experiments}

Virgin TPEE and virgin PBT in different ratios were mixed and dry-blended with the antioxidant and compatibilizer to make the polymeric blends. Then, the mixed, dry blend was placed into the hopper of the $45 \mathrm{~L} / \mathrm{D}$ twin extruder. The temperature of the extruder was kept at $245^{\circ} \mathrm{C}$ in the feeding zone, $265^{\circ} \mathrm{C}$ in the melting zone, and $270^{\circ} \mathrm{C}$ at the die. The screw speed and polymer input were controlled using a Brabender gravimetric control unit. The melt strand was cooled in water and cut with a pelletizer into $4 \mathrm{~mm}$ pieces. The pellets were dried for $4 \mathrm{hrs}$ at $80^{\circ} \mathrm{C}$ and then used to make mechanical testing bars with an injection molding machine.

In the second step, the polymer blends (TPEE and PBT) were mixed with either clay or Teflon (PTFE). The mix was added to the extruder hopper and blended using the same parameters as outlined above. Injection molded samples were prepared with different shapes and thicknesses depending on the type of test and analysis to be performed.

\section{Formulation}

Table 1 shows the initial formulations of the polymeric blends and compares test results from the blends with those of virgin Skypel G155D and Hytrel.

Virgin TPEE with a thermal stabilizer was used in experiment 1 . In experiments 2 and 3, PBT with different weight percentages was used in addition to thermal additives and compatibilizer. $10 \%$ PETG polymer was added to $15 \%$ PBT in experiment 4 . The goal of changing the weight percentage of PBT is to observe the effect of different blend ratios on the mechanical properties of the virgin TPPE compounded in experiment 1.

\section{Characterization}

5.1. Mechanical Testing. Flexural strength and flexural modulus were tested according to ASTM D790 using a universal Instron testing machine, USA. The testing samples had a span size of $10 \mathrm{~cm}$, a width of $6.4 \mathrm{~cm}$, and a thickness of $3.2 \mathrm{~mm}$. The cross-head speed was set to $12.5 \mathrm{~mm} / \mathrm{min}$. The tensile strength and moduli were measured as per ASTM D638 on a universal Instron testing machine, USA, with a cross-head speed of $50 \mathrm{~mm} / \mathrm{min}$. 


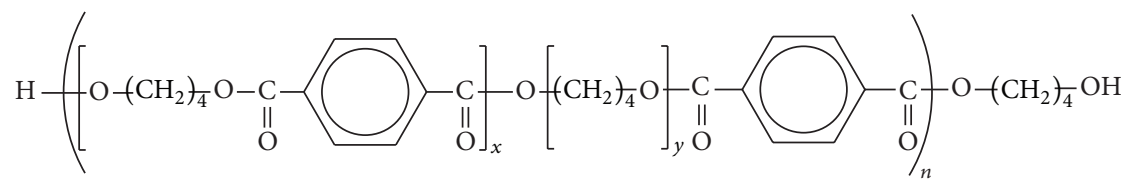

(a)<smiles>CCCCCCCCC(C)(C)C(=O)c1ccc(C(=O)OC(C)(C)C)cc1</smiles>

(b)

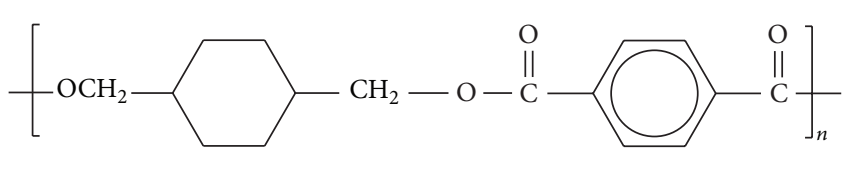

(c)<smiles>C[NH+]([In])[IH]</smiles>

(d)

FIgURE 1: (a) TPEE structure: the left side is the soft block and the right side is the hard block. (b) PBT structure. (c) PETG structure. (d) Organo modified clay 93A ( $\mathrm{T}$ is tallow).

TABLE 1: Initial formulation (wt.\%) of the polymeric blends.

\begin{tabular}{lcccccrr}
\hline Experiment \# & TPEE G155D & PBT (1200-211M) & IF-168 & IF-1010 & MA & PETG (KN100) & Total \\
\hline 1 & 54.50 & 45.00 & 0.20 & 0.20 & 0.50 & 0.00 & 100.4 \\
2 & 74.50 & 25.00 & 0.20 & 0.20 & 0.50 & 0.00 & 100.4 \\
3 & 74.50 & 15.00 & 0.20 & 0.20 & 0.50 & 10.00 & 100.4 \\
\hline
\end{tabular}

5.2. Thermal Testing. Heat distortion testing (HDT) was measured as per ASTM D648 using specimens that were $127 \mathrm{~cm}$ long, $12.5 \mathrm{~mm}$ wide, and $6.4 \mathrm{~mm}$ thick. The test was conducted at a stress of $0.45 \mathrm{MPa}$ and a heating rate of $2^{\circ} \mathrm{C} / \mathrm{min}$ using an HDT measurement device and Instron HDT-VCAT, USA. The degradation of the composites with temperature was determined via thermogravimetric analysis (TGA) in air with a TGA Q50 system (TA instrument). The initial temperature was set to $100^{\circ} \mathrm{C}$ and raised to $800^{\circ} \mathrm{C}$ at a rate of $10^{\circ} \mathrm{C} / \mathrm{min}$. Thermal analysis was carried out using a DSC Q2000 system (TA Instruments) at a heating rate of $10^{\circ} \mathrm{C} / \mathrm{min}$ under nitrogen. The glass transition temperature $\left(T_{g}\right)$ and melting temperature $\left(T_{m}\right)$ were taken from the DSC thermographs.

5.3. XRD Analysis. XRD data were collected on Rigaku $\mathrm{D} / \mathrm{MAX}-2500 / \mathrm{PC}$ diffractometer with a $\mathrm{Cu} \mathrm{K} \alpha$ radiation source operated at a voltage of $40 \mathrm{kV}$ and current of $100 \mathrm{~mA}$. The molded samples were scanned from 1.5 to $10^{\circ}$ at a $1^{\circ} \mathrm{min}^{-1}$ scan rate.

5.4. Microstructure and Morphology Analysis. SEM and TEM were used to analyze the fracture surfaces and dispersion of nanoparticles. An SEM AIS2300C from Seron Technologies Inc., Republic of Korea, was used to analyze the fracture surfaces of the composites. Samples were gold-coated prior to imaging. Transmission electron microscopy (TEM, JEM2100F, JEOL) was used to observe the dispersion of the PTFE and clay.

\section{Results and Discussion}

Table 3 shows mechanical test results from the different polymer blends made with Skypel G155D compared to mechanical properties of Hytrel 7246. Hytrel is a trademarked product and is used for molding baffle plates (Figure 1) used in automobiles. This investigation emphasized improving the mechanical and thermal properties compared with the current trademarked products used by the automotive industry.

As observed from experiments 1-3, various blends of PBT with TPEE showed improved flexural strength, flexural modulus, tensile strength, and elongation compared with Skypel and Hytrel (Figure 1(a)). The HDT of the blends, however, which is one of the most important criteria for baffle plate applications, was 107,104 , and $66^{\circ} \mathrm{C}$ in experiments 1 , 2 , and 3 , respectively, which was lower than that of Hytrel. For experiment 3, the mechanical properties were within acceptable ranges; however, the HDT was quite low $\left(66.0^{\circ} \mathrm{C}\right)$ due to the use of $10 \%$ PETG and $15 \%$ PBT. The low HDT value in ex-3 is explained using the low HDT value of PETG $\left(60^{\circ} \mathrm{C}\right)$ compared to the high $\mathrm{HDT}$ value $\left(150^{\circ} \mathrm{C}\right)$ found in virgin PBT. Since this part is to be used under the hood of an automobile, where temperatures are often in excess of 
TABLE 2: Formulations (wt.\%) of the polymeric blends with nanoclay and PTFE.

\begin{tabular}{lccccccrr}
\hline Experiment \# & TPE G155D & PBT (1200-211M) & IF-168 & IF-1010 & MA & PTFE (TP200) & Clay cloisite 93A & Total \\
\hline 4 & 49.100 & 50.000 & 0.200 & 0.200 & 0.500 & 0.000 & 0.000 & 100.000 \\
5 & 48.600 & 50.000 & 0.200 & 0.200 & 0.500 & 0.00 & 0.500 & 100.000 \\
6 & 48.600 & 50.000 & 0.200 & 0.200 & 0.500 & 0.500 & 0.000 & 100.000 \\
\hline
\end{tabular}

TABLE 3: Mechanical test results for polymer blends with different ratios.

\begin{tabular}{|c|c|c|c|c|c|c|c|}
\hline \multirow{3}{*}{ Experiment \# } & \multirow{3}{*}{ Density $\left(\mathrm{g} / \mathrm{cm}^{3}\right)$} & $\mathrm{MI}(\mathrm{g} / 10 \mathrm{~min})$ & $\operatorname{HDT}\left({ }^{\circ} \mathrm{C}\right)$ & $\begin{array}{c}\text { Flexural } \\
\text { strength }(\mathrm{MPa})\end{array}$ & $\begin{array}{c}\text { Flexural } \\
\text { modulus (MPa) }\end{array}$ & $\begin{array}{c}\text { Tensile strength } \\
(\mathrm{MPa})\end{array}$ & $\begin{array}{c}\text { Tensile } \\
\text { elongation (\%) }\end{array}$ \\
\hline & & \multirow{2}{*}{$240^{\circ} \mathrm{C} / 2.16 \mathrm{~kg}$} & \multirow{2}{*}{$0.45 \mathrm{MPa}$} & \multicolumn{2}{|c|}{$T=6.4$} & \multicolumn{2}{|c|}{$T=3.2$} \\
\hline & & & & \multicolumn{2}{|c|}{$12.5 \mathrm{~mm} / \mathrm{min}$} & \multicolumn{2}{|c|}{$50 \mathrm{~mm} / \mathrm{min}$} \\
\hline Hytrel & 1.25 & 17.4 & 119.6 & 20.14 & 421.1 & 35.8 & 741.7 \\
\hline Skypel & 1.18 & 20.0 & 105.0 & 18.20 & 210.0 & 34.0 & 600.0 \\
\hline 1 & 1.25 & 41.0 & 107.0 & 31.00 & 778.0 & 35.1 & 929.0 \\
\hline 2 & 1.22 & 33.0 & 104.0 & 20.40 & 446.0 & 29.6 & 924.0 \\
\hline 3 & 1.22 & 29.0 & 66.0 & 20.80 & 457.0 & 28.1 & 924.0 \\
\hline
\end{tabular}

$100^{\circ} \mathrm{C}$, the HDT of the product must be higher than $120^{\circ} \mathrm{C}$. The reason for the lower HDTs in experiments 1 and 2 could potentially be due to the fact that the virgin PBT used in these experiments is believed to be lower than 25-45 wt.\%. Higher flexural modulus was observed due to the strong interfacial bonding between the two miscible polymers which were further enhanced by the maleic compatibilizer. The mechanical properties from ex-1 were higher than those from ex-2, since the amount of PBT in ex-1 was higher (45\%) than that in ex-2 (25\%). As shown in the previous experimental results, as the amount of virgin PBT increased (Table 2), there was an increase in the HDT value and other mechanical properties. These results have been summarized in Table 4.

In these experiments (experiments 4-6), $50 \mathrm{wt}$ \% PBT was added. As the amount of PBT increased from 45\% (ex1) to $50 \%$, flexural strength was increased by $96 \%$ in ex4 compared to Skypel and by $76 \%$ compared to Hytrel. There was also an effect from the addition of PTFE and nanoclay in experiments 5 and 6 . The addition of only $0.5 \%$ PTFE or $0.5 \%$ nanoclay resulted in above $100 \%$ or $85 \%$ improvement in flexural strength, respectively, compared with Skypel and Hytrel. The flexural modulus significantly improved by $340 \%$ after increasing the PBT amount to $50 \%$ through blending with Skypel. A 126 to $129 \%$ improvement in flexural modulus was observed after the addition of $0.5 \%$ clay and the PTFE additives when compared with Hytrel. The tensile strength and elongation were also found to improve accordingly. Further improvements in flexural strength and flexural modulus resulted from the addition of a small amount of PTFE and nanoclay. This change was attributed to the homogeneous dispersion and good interfacial bonding of PTFE within the TPEE matrix and the homogenous and good exfoliation along with intercalation of clay in the TPEE matrix $[24,25]$. There is a good increment correlation observed between flexural strength, flexural modulus, elongation, and HDT and it is summarized in Table 4. Figure 2 shows the stress-strain (S-S) curves of the composites used in this

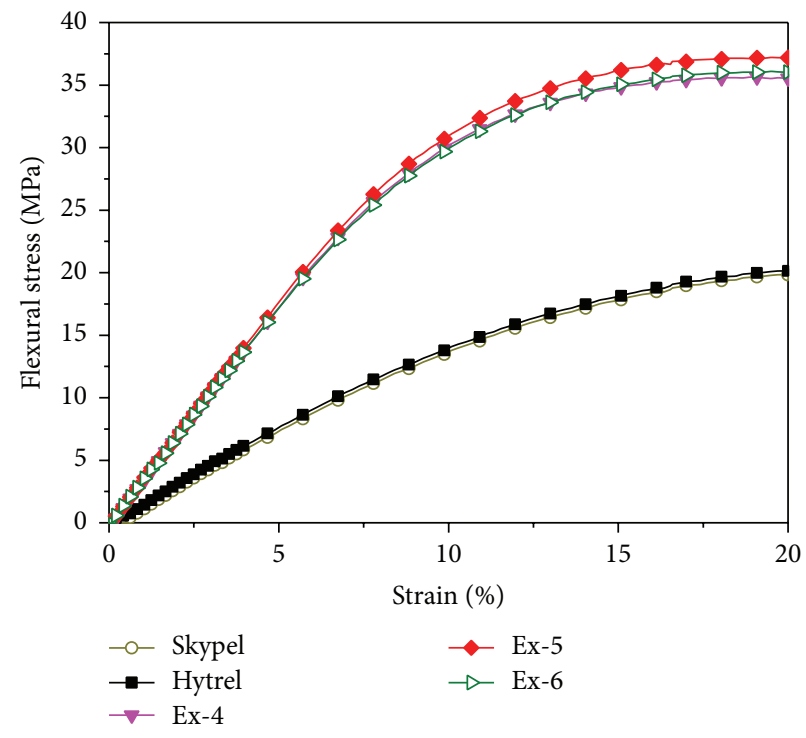

FIGURE 2: Stress-strain (S-S) curve of the composites.

experiment. The S-S curve clearly proves that blending of Skypel TPEE with PBT followed by a small amount of PTFE or nanoclay improves the mechanical properties of the polymeric blends. The increase in flexural strength and flexural modulus is due to the enhanced intermixing of the polymeric blends and the homogeneous dispersion of the nano-PTFE and clay particles. A maximum improvement was observed for the case of the clay dispersion, which might be explained by the formation of exfoliated clay particles in the polymeric matrix. The improvement in tensile properties and tensile elongation can also be explained by the improved interfacial bonding between the polymers and the formation of nanoparticles [24]. These results were supported by SEM and TEM micrographs, as shown in Figures 3(a)-3(d) and 7(a)-7(b), respectively. 
TABLE 4: Mechanical test results of the different nanocomposites.

\begin{tabular}{|c|c|c|c|c|c|c|c|}
\hline \multirow{3}{*}{ Batch number } & \multirow{3}{*}{ Density $\left(\mathrm{g} / \mathrm{cm}^{3}\right)$} & $\mathrm{MI}(\mathrm{g} / 10 \mathrm{~min})$ & $\operatorname{HDT}\left({ }^{\circ} \mathrm{C}\right)$ & $\begin{array}{c}\text { Flexural } \\
\text { strength }(\mathrm{MPa})\end{array}$ & $\begin{array}{c}\text { Flexural } \\
\text { modulus }(\mathrm{MPa})\end{array}$ & $\begin{array}{l}\text { Tensile strength } \\
(\mathrm{MPa})\end{array}$ & $\begin{array}{c}\text { Tensile } \\
\text { elongation (\%) }\end{array}$ \\
\hline & & \multirow{2}{*}{$240^{\circ} \mathrm{C} / 2.16 \mathrm{~kg}$} & \multirow{2}{*}{$0.45 \mathrm{MPa}$} & \multicolumn{2}{|c|}{$T=6.4$} & \multicolumn{2}{|c|}{$T=3.2$} \\
\hline & & & & \multicolumn{2}{|c|}{$12.5 \mathrm{~mm} / \mathrm{min}$} & \multicolumn{2}{|c|}{$50 \mathrm{~mm} / \mathrm{min}$} \\
\hline Hytrel & 1.25 & 17.4 & 119.6 & 20.14 & 421.1 & 35.8 & 741.7 \\
\hline Skypel & 1.18 & 20.0 & 105.0 & 18.20 & 210.0 & 34.0 & 600.0 \\
\hline Ex-4 & 1.25 & 46.0 & 102.0 & 35.60 & 926.0 & 36.6 & 934.0 \\
\hline Ex-5 & 1.25 & 50.0 & 139.0 & 37.10 & 954.0 & 37.7 & 921.0 \\
\hline Ex-6 & 1.24 & 47.0 & 135.0 & 36.10 & 947.0 & 36.4 & 753.0 \\
\hline
\end{tabular}

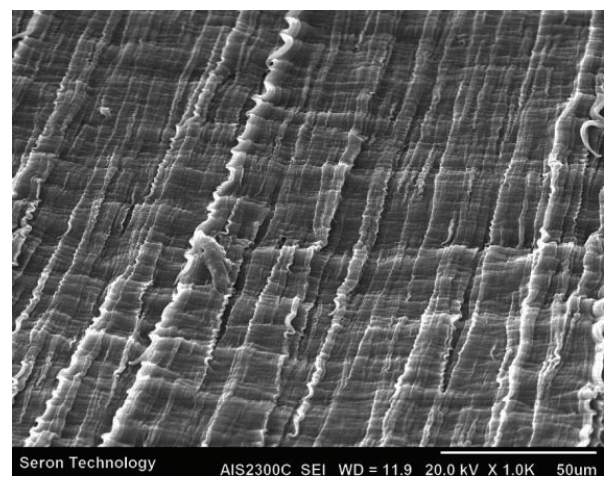

(a)

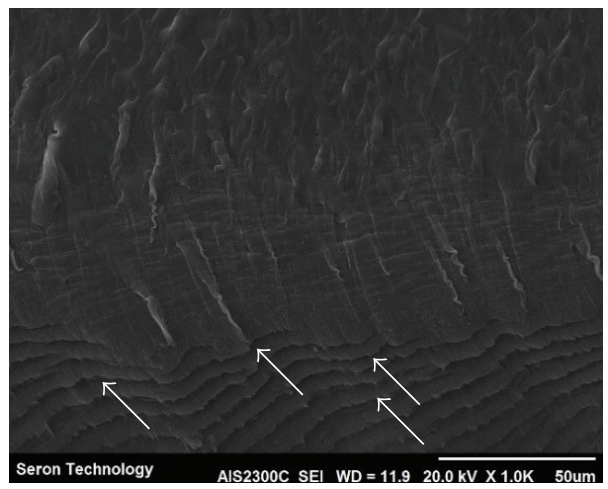

(c)

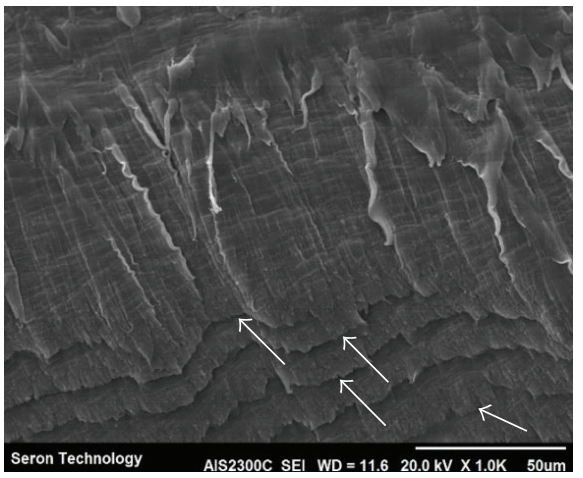

(b)

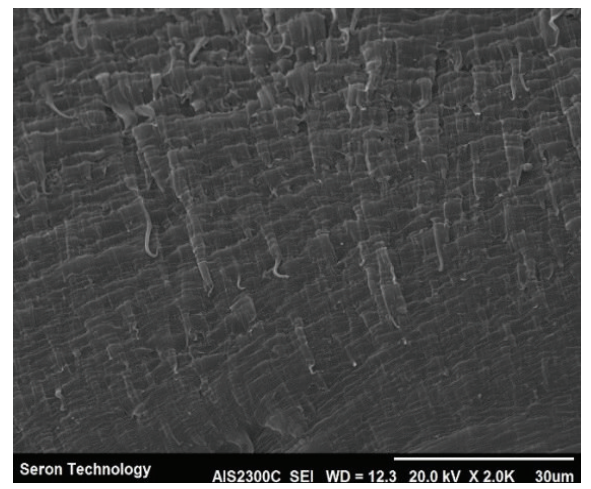

(d)

FIGURE 3: SEM micrographs of (a) Hytrel, (b) TPEE blends, (c) clay nanocomposites, and (d) PTFE nanocomposites.

The phase morphologies of the polymeric blends and nanocomposites were examined by SEM. These images were used to explain the higher flexural and tensile strength of the blends and composites. The images were taken of the fracture surfaces from pulled tensile strength specimens. Only the TPEE (Hytrel) in Figure 3(a) shows the continuous nature of the fracture throughout the specimen. No fibrils or elongated polymeric parts were observed. This fracture morphology confirmed the lower toughness of the polymeric materials and thus the lower flexural and tensile strength and flexural modulus compared with the polymeric blends. However, the polymeric blends made from TPEE and PBT clearly show a different morphology in Figure 3(b). Strong interfacial bonding between the polymeric materials (seen in the upper region of the micrograph) was confirmed from the fibrous nature of the elongated zone. Moreover, in the lower part of the micrograph, the river creek and steps (arrow mark) reveal the higher toughness and high strength of the composites. A high degree of miscibility between TPEE and PBT is clearly observed and can be confirmed from the continuous nature of the fracture seen throughout the specimen.

The nearly continuous fracture morphology seen in the clay dispersed blends is shown in Figure 3(c). However, the more fibrous nature observed in the upper part of the micrographs suggests enhanced interfacial bonding between the polymeric blends. More river creek-like structures with more steps were observed, confirming the toughened nature of the nanocomposites in comparison with the polymeric blends. 


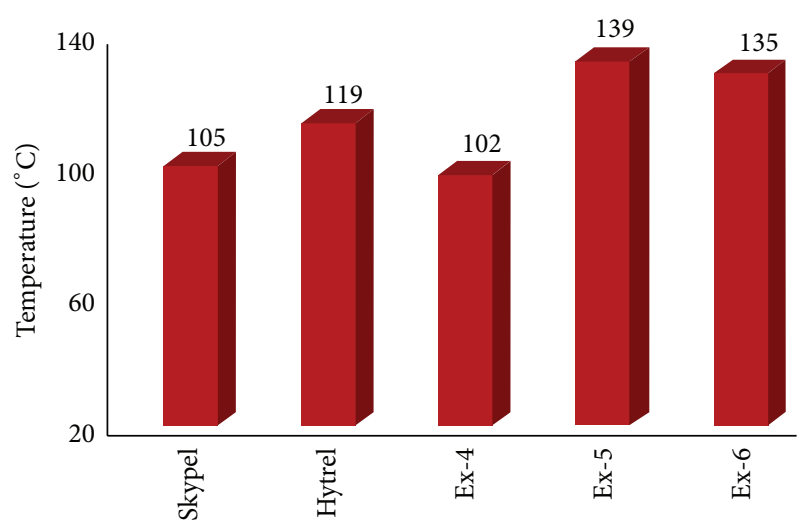

FIGURE 4: HDT measurement value of the composites.

Agglomerated domains were not observed, confirming the homogenous dispersion of the clay. Micrographs of the PTFE dispersed nanocomposites are shown in Figure 3(d). The fibrous nature of the polymer can be observed in the upper part of the micrographs; however, the river creeklike features and steps (arrow mark) were observed throughout the fracture specimen. This type of fracture surface should show maximum toughness. However, according to our tensile stress-strain curve, the PTFE nanocomposites showed slightly lower strength values compared with the clay dispersed nanocomposites. This might be due to the presence of small domains of PTFE (white part of the micrograph) and agglomeration which was later confirmed by TEM.

The thermal properties of the composites were analyzed via HDT measurements. There was a $14.7 \%$ reduction in HDT compared to Hytrel when only TPEE and PBT were blended (ex-4). There was a significant improvement in observed HDT in experiments 5 and 6. In these experiments, $0.5 \%$ clay and $0.5 \%$ PTFE additions increased the HDT by $32 \%$ and $28 \%$, respectively, when compared with Skypel TPEE; however, it is $16 \%$ and $13 \%$ when compared with Hytrel TPEE. Figure 4 shows how the HDT values improved. The improvement in HDT can be explained by the addition of PTFE and the presence of the compatibilizer, which created strong interfacial bonds between the PTFE and matrix blend. Furthermore, increases in the amount of clay suggest that exfoliation occurred by the addition of the clay [26].

The thermal properties were also examined by TGA and DSC analysis. To elucidate the thermal behavior of TPEE and blend polymeric composites, DSC analyses were conducted and the relative scans were obtained; these are shown in Figure 5. The Hytrel polymer shows $T_{g}$ at $93.2^{\circ} \mathrm{C}$, but the peak is not sharp when compared to blended composites in similar temperature ranges. A single sharp peak for $T_{g}$ at 93.4, 92.9, and $94.4^{\circ} \mathrm{C}$ in experiments $4-6$, respectively, confirms homogenous mixing/blending between TPEE and PBT. A slight increase in $T_{g}$ was observed after the addition of PTFE and nanoclay. These results reveal that there was no phase separation between the polymeric blends and that there was good interfacial mixing between the two polymeric materials. The hard segments of the TPEE polymeric materials come

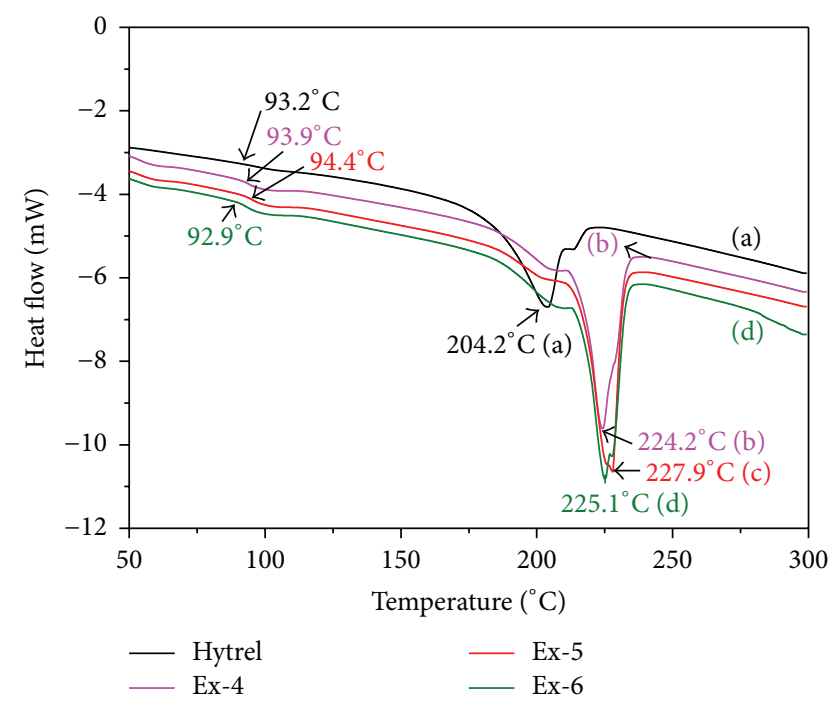

FIgUre 5: DSC curves of (a) Hytrel, (b) TPEE-PBT blends, (c) clay nanocomposites, and (d) PTFE nanocomposites.

from the PBT. Thus, blending with PBT polymer showed good miscibility and formation of single phase matrix. The enhanced intermiscibility and thermodynamic equilibrium between the two polymeric materials might be due to the presence of the maleic compatibilizer used in the experiments. Many researchers using maleic compatibilizer have seen similar results $[27,28]$. The melting point of the polymeric blended composites and the PTFE and clay dispersed composites was $25^{\circ} \mathrm{C}$ higher than the melting point of the Hytrel polymer. The highest melting temperature, $227.9^{\circ} \mathrm{C}$, resulted from the addition of the nanoclay particles. The achievement of the higher melting temperature in the blends and PTFE and clay dispersed composites was a result of the good interfacial bonding and dispersion within the base matrix, which was enhanced by the MA compatibilizer [2931].

Figure 6 shows a typical TGA of weight loss as a function of temperature in air for the four samples. It is clear from the TGA figure that the thermal stability (residue\%) at $800^{\circ} \mathrm{C}$ of the clay and PTFE dispersed composites is much higher than that of the polymeric blends and Hytrel polymers. Although the PTFE composite showed an early onset degradation temperature at $352^{\circ} \mathrm{C}$, this might be due to the evaporation of low molecular weight organic molecules that are associated with it (according to the manufacturer). The total weight loss at $800^{\circ} \mathrm{C}$ is still much lower compared to the other composites. Similar results were also observed when PTFE was mixed with polyamide $[32,33]$. The clay dispersed composite in ex-5 shows good thermal performance (high residue), even at $800^{\circ} \mathrm{C}$. Although the onset degradation temperature was the same for the polymeric blends and Hytrel, the residue was much higher, even at higher temperatures. The stable morphology of the clay dispersed phase and the presence of exfoliated silicate layered structures may be the main reason for the enhancement in the thermal stability of the clay 


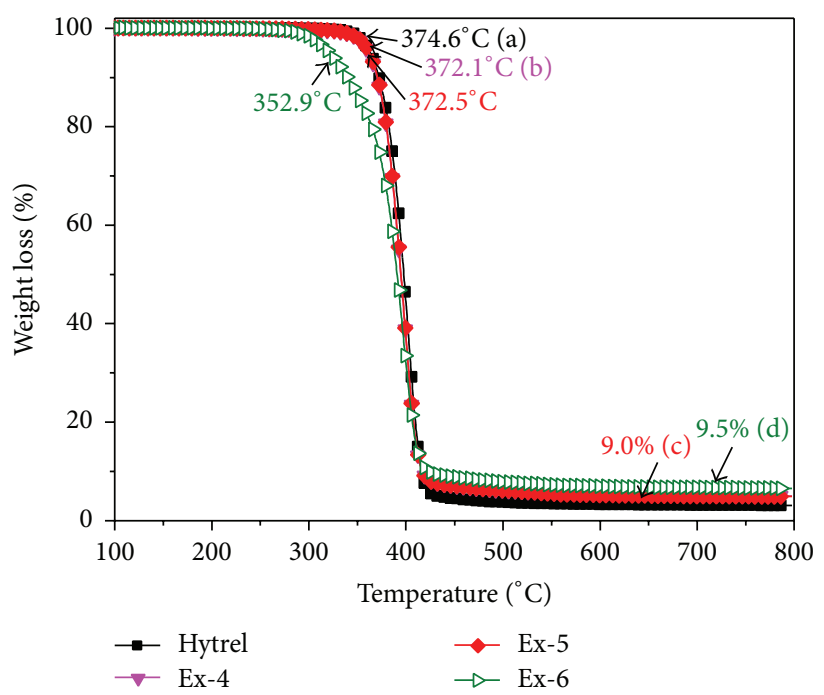

Figure 6: TGA curves of (a) Hytrel, (b) TPEE-PBT blends, (c) clay nanocomposites, and (d) PTFE nanocomposites.

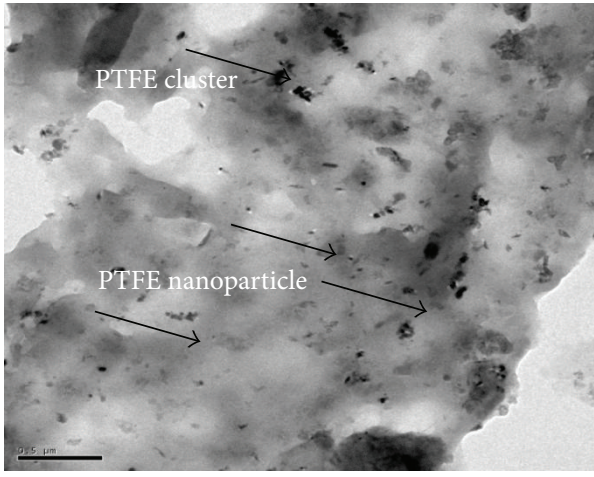

(a)

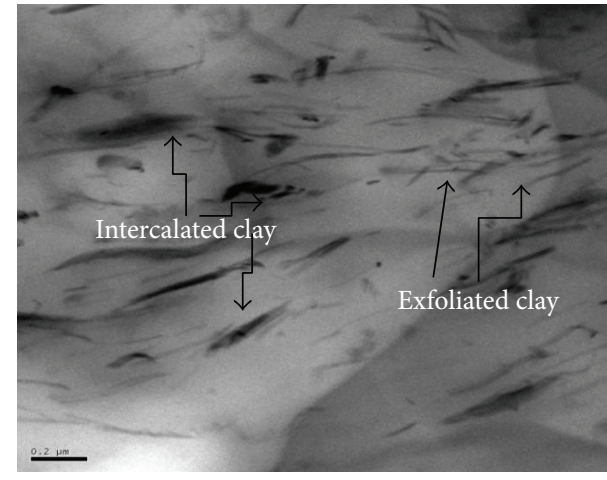

(b)

FIgURE 7: TEM images of (a) PTFE nanocomposites and (b) clay nanocomposites.

composites. The higher thermal stability of the PTFE dispersed composites can also be explained by the homogeneous dispersion of PTFE particles and the forming of nanoparticles during the extrusion process. Furthermore, increasing the barrier properties, which can slow down oxygen diffusion, will hinder oxidation processes $[27,34]$.

The addition of clay in the polymeric materials results in significant improvements in the mechanical properties. Many researchers are studying the dispersion of nanomaterials in polymeric materials to improve not only their mechanical properties but also their thermal and flame retardant properties. However, the dispersibility of nanomaterials is one of the major hurdles in improving these properties. The dispersion of the PTFE and clay was observed by TEM analysis and is shown in Figures 7(a) and 7(b). There was good dispersion of PTFE particles with only some agglomeration. The interface between the polymer and PTFE particles was found to be strong, leading to the higher mechanical properties of the polymeric composites. The TEM micrographs of the PTFE composites also reveal the formation of nanoPTFE particles that formed during the compounding process.
The homogeneous dispersion and exfoliated nature along with intercalation of the nanoclay were also confirmed by TEM, as shown in Figure 7(b). It was observed that the clay particles are perfectly exfoliated in the polymeric blends and that needle shaped structures were generated. Some parts were (black thick structure) also observed which are believed to be intercalated nanoclay. Such a structure (exfoliation) contributes to the higher mechanical and thermal properties of the polymeric nanocomposites [24, 35, 36].

To confirm the dispersion and examine the intercalation and exfoliation of clay by monitoring the reflection from silicate layer in the clay, XRD analysis was investigated. The XRD patterns of the virgin clay, clay nanocomposites, and PTFE nanocomposites are shown in Figure 8 . The virgin clay showed distinct peak at 2 theta 3.2 degree having $d$ spacing (clay interlayer gap) of $2.74 \mathrm{~nm}$. However, in TPEE clay nanocomposites, 2 theta peak was shifted to lower value at 2.5 degree. The interlayer gap of clays was increased from $2.74 \mathrm{~nm}$ to $3.47 \mathrm{~nm}$. XRD pattern suggests that the increase in $d$ spacing would be simply defined as intercalated; however, the TEM images showed that although there were indeed 


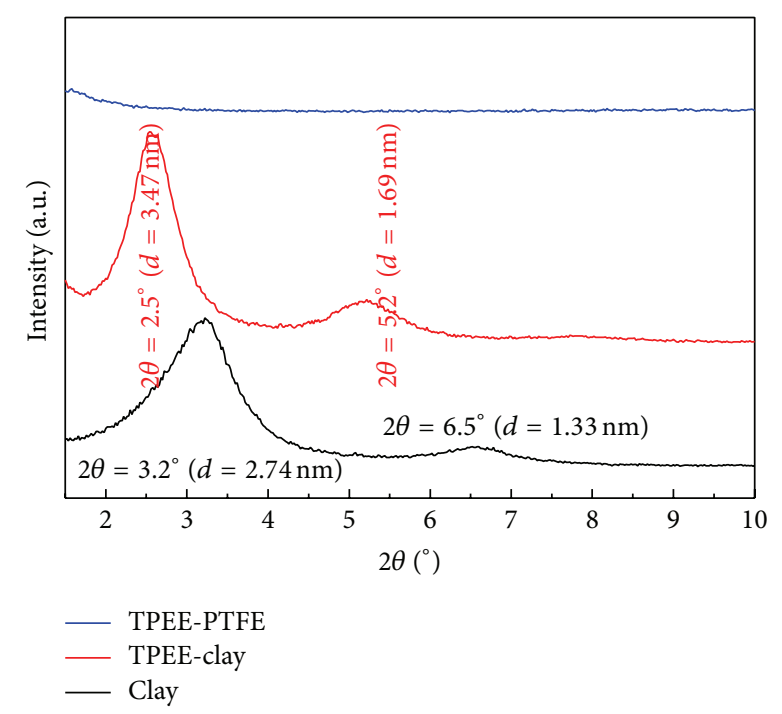

FIGURE 8: XRD pattern of virgin clay, clay nanocomposites, and PTFE nanocomposites.

intercalated multilayer crystallites present, single exfoliated silicate layers were also prevalent. The nature of the peaks at 2.5 and 5.2 theta suggests that diversity of structures coexisted as pure exfoliated structures would not give peaks by XRD [37]. Similar results were also observed in polymer clay nanocomposites and suggested that nanocomposites would fully show no peaks in 2-3 theta region; however, an increase in $d$ spacing of $3.47 \mathrm{~nm}$ indicates a wider separation of silicate layers associated with intercalation and exfoliation [38].

\section{Conclusion}

In this experiment, we observed that the mechanical properties of PBT improved significantly by only blending it with TPEE; however, the thermal properties did not improve. The mechanical properties as well as the thermal properties were improved significantly by the addition of a small amount of PTFE or nanoclay, attributable to the homogeneous dispersion of PTFE and clay particles at the nanolevel. The improvements in mechanical and thermal properties of the dispersed clay and polymer blends were achieved by the intercalation and exfoliation of the clay particles. We successfully molded novel polymer blends of PTFE and clay nanocomposites with good processing properties and significantly higher mechanical properties and thermal properties, in terms of the HDT. The product was tested at high temperatures as a baffle plate for use under the hood of an automobile.

\section{Competing Interests}

The authors declare that there are no competing interests regarding the publication of this paper.

\section{Acknowledgments}

This work was supported by a grant from the Fundamental R\&D Program for Core Technology of Materials (10050890, chalcogenide nanostructure-based room temperature $\left(25^{\circ} \mathrm{C}\right)$ $\mathrm{H}_{2}$ and $\mathrm{H}_{2} \mathrm{~S}$ gas sensors with low power consumption) funded by the Ministry of Trade, Industry \& Energy, Republic of Korea (MTIE, Korea) under Grant no. 10038362.

\section{References}

[1] D. R. Paul and S. Newman, Polymer Blends, Academic Press, New York, NY, USA, 1978.

[2] L. A. Utracki, Polymer Alloys and Blends, Hanser Publishers, Munich, Germany, 1989.

[3] N. Hasegawa, M. Kawasumi, M. Kato, A. Usuki, and A. Okada, "Preparation and mechanical properties of polypropyleneclay hybrids using a maleic anhydride-modified polypropylene oligomer," Journal of Applied Polymer Science, vol. 67, no. 1, pp. 87-92, 1998.

[4] J. Li, C. Zhou, and W. Gang, "Study on nonisothermal crystallization of maleic anhydride grafted polypropylene/montmorillonite nanocomposite," Polymer Testing, vol. 22, no. 2, pp. 217223, 2003.

[5] C. M. Koo, M. J. Kim, M. H. Choi, S. O. Kim, and I. J. Chung, "Mechanical and rheological properties of the maleated polypropylene-layered silicate nanocomposites with different morphology," Journal of Applied Polymer Science, vol. 88, no. 6, pp. 1526-1535, 2003.

[6] P. Pötschke and D. R. Paul, "Formation of Co-continuous structures in melt-mixed immiscible polymer blends," Journal of Macromolecular Science Part C: Polymer Reviews, vol. 43, no. 1, pp. 87-141, 2003.

[7] J. Li, P. L. Ma, and B. D. Favis, "The role of the blend interface type on morphology in cocontinuous polymer blends," Macromolecules, vol. 35, no. 6, pp. 2005-2016, 2002.

[8] N. K. Kaforglou, "Thermomechanical stuidies of semicrystaline polyether-ester copolymers," Journal of Applied Polymer Science, vol. 21, pp. 543-554, 1977.

[9] Y. Nagai, T. Ogawa, L. Y. Zhen, Y. Nishimoto, and F. Ohishi, "Analysis of weathering of thermoplastic polyester elastomersI. Polyether-polyester elastomers," Polymer Degradation and Stability, vol. 56, no. 1, pp. 115-121, 1997.

[10] B. M. Walker, Handbook of Thermoplastic Elastomer, vol. 1, Litton Education, New York, NY, USA, 1st edition, 1979.

[11] A. D. Joshi, “TPO vs. PVC for automotive interior," Journal of Coated Fabrics, vol. 23, pp. 67-73, 1993.

[12] L. M. Pariser, "Copolyester: the fuel resistant thermoplastic elastomer," Journal of Elastomers \& Plastics, vol. 15, no. 3, pp. 146-158, 1983.

[13] A. Usuki, Y. Kojima, M. Kawasumi et al., "Synthesis of nylon 6-clay hybrid," Journal of Materials Research, vol. 8, no. 5, pp. 1179-1184, 1993.

[14] A. Usuki, A. Koiwai, Y. Kojima et al., "Interaction of nylon 6clay surface and mechanical properties of nylon 6-clay hybrid," Journal of Applied Polymer Science, vol. 55, no. 1, pp. 119-123, 1995.

[15] K. Yano, A. Usuki, A. Okada, T. Kurauchi, and O. Kamigaito, "Synthesis and properties of polyimide-clay hybrid," Journal of Polymer Science Part A: Polymer Chemistry, vol. 31, no. 10, pp. 2493-2498, 1993.

[16] N. Hasegawa, H. Okamoto, M. Kawasumi, and A. Usuki, "Preparation and mechanical properties of polystyrene-clay hybrids," Journal of Applied Polymer Science, vol. 74, no. 14, pp. 3359-3364, 1999. 
[17] M. Kawasumi, N. Hasegawa, M. Kato, A. Usuki, and A. Okada, "Preparation and mechanical properties of polypropylene-clay hybrids," Macromolecules, vol. 30, no. 20, pp. 6333-6338, 1997.

[18] P. Maiti, P. H. Nam, M. Okamoto, N. Hasegawa, and A. Usuki, "Influence of crystallization on intercalation, morphology, and mechanical properties of polypropylene/clay nanocomposites," Macromolecules, vol. 35, no. 6, pp. 2042-2049, 2002.

[19] M. Y. Gelfer, H. H. Song, L. Liu et al., "Effects of organoclays on morphology and thermal and rheological properties of polystyrene and poly(methyl methacrylate) blends," Journal of Polymer Science, Part B: Polymer Physics, vol. 41, article 44, 2002.

[20] Y. Wang, Q. Zhang, and Q. Fu, "Compatibilization of immiscible poly(propylene)/polystyrene blends using clay," Macromolecular Rapid Communications, vol. 24, no. 3, pp. 231-235, 2004.

[21] K. Yurekli, A. Karim, E. J. Amis, and R. Krishnamoorti, "Influence of layered silicates on the phase-separated morphology of PS-PVME blends," Macromolecules, vol. 36, no. 19, pp. 72567267, 2003.

[22] Y. Li and H. Shimizu, "Novel morphologies of poly(phenylene oxide) (PPO)/polyamide 6 (PA6) blend nanocomposites," Polymer, vol. 45, no. 22, pp. 7381-7388, 2004.

[23] H.-J. Sue, K. T. Gam, N. Bestaoui, N. Spurr, and A. Clearfield, "Epoxy nanocomposites based on the synthetic $\alpha$-zirconium phosphate layer structure," Chemistry of Materials, vol. 16, no. 2, pp. 242-249, 2004.

[24] M. Jisheng, S. Zhang, and Z. Qi, "Synthesis and characterization of elastomeric polyurethane/clay nanocomposites," Journal of Applied Polymer Science, vol. 82, no. 6, pp. 1444-1448, 2001.

[25] A. J. Varma, M. D. Deshpamde, and V. M. Nadkarni, "Morphology and mechanical properties of silicate filled polyurethane elastomers based on castor oil and polymeric MDI," Die Angewandte Makromolekulare Chemie, vol. 132, no. 1, pp. 203209, 1985.

[26] R. Nalini, S. Nagarajan, and B. S. R. Reddy, "Polypropyleneblended organoclay nanocomposites-preparation, characterisation and properties," Journal of Experimental Nanoscience, vol. 8, no. 4, pp. 480-492, 2013.

[27] S. S. Ray and M. Bousmina, "Effect of organic modification on the compatibilization efficiency of clay in an immiscible polymer blend," Macromolecular Rapid Communications, vol. 26, no. 20, pp. 1639-1646, 2005.

[28] R. Nalini, S. Nagarajan, and B. S. Reddy, "Thermoplastic polyolefin nanocomposites: effect of mechanical, thermal, and morphological properties," Journal of Reinforced Plastics \& Composites, vol. 30, no. 4, pp. 319-324, 2011.

[29] Y. Zhang, W. Han, and C.-F. Wu, "Preparation and properties of polypropylene/organo-vermiculite nanocomposites," Journal of Macromolecular Science, Part B: Physics, vol. 48, no. 5, pp. 967978, 2009.

[30] B. Z. Jang, D. R. Uhlmann, and J. B. Vander Sande, "Rubbertoughening in polypropylene," Journal of Applied Polymer Science, vol. 30, no. 6, pp. 2485-2504, 1985.

[31] W. G. Zheng, Y. H. Lee, and C. B. Park, "Use of nanoparticles for improving the foaming behaviors of linear PP," Journal of Applied Polymer Science, vol. 117, no. 5, pp. 2972-2979, 2010.

[32] G. Pompe, L. Haubler, P. Pötschke et al., "Reactive polytetrafluoroethylene/polyamide compounds. I. Characterization of the compound morphology with respect to the functionality of the polytetrafluoroethylene component by microscopic and differential scanning calorimetry studies," Journal of Applied Polymer Science, vol. 98, no. 3, pp. 1308-1316, 2005.
[33] G. Pompe, L. Häußler, G. Adam et al., "Reactive polytetrafluoroethylene/polyamide 6 compounds. II. Study of the reactivity with respect to the functionality of the polytetrafluoroethylene component and analysis of the notched impact strength of the polytetrafluoroethylene/polyamide 6 compounds," Journal of Applied Polymer Science, vol. 98, no. 3, pp. 1317-1324, 2005.

[34] M. Y. Gelfer, C. Burger, B. Chu et al., "Relationships between structure and rheology in model nanocomposites of ethylene-vinyl-based copolymers and organoclays," Macromolecules, vol. 38, no. 9, pp. 3765-3775, 2005.

[35] K. Y. Lee and L. A. Goettler, "Structure-property relationships in polymer blend nanocomposites," Polymer Engineering \& Science, vol. 44, no. 6, pp. 1103-1111, 2004.

[36] C. H. Dan, M. H. Lee, Y. D. Kim, B. H. Min, and J. H. Kim, "Effect of clay modifiers on the morphology and physical properties of thermoplastic polyurethane/clay nanocomposites," Polymer, vol. 47, no. 19, pp. 6718-6730, 2006.

[37] A. B. Morgan and J. W. Gilman, "Characterization of polymerlayered silicate (clay) nanocomposites by transmission electron microscopy and X-ray diffraction: a comparative study," Journal of Applied Polymer Science, vol. 87, no. 8, pp. 1329-1338, 2002.

[38] T. S. Ellis and J. S. D’Angelo, "Thermal and mechanical properties of a polypropylene nanocomposite," Journal of Applied Polymer Science, vol. 90, no. 6, pp. 1639-1647, 2003. 

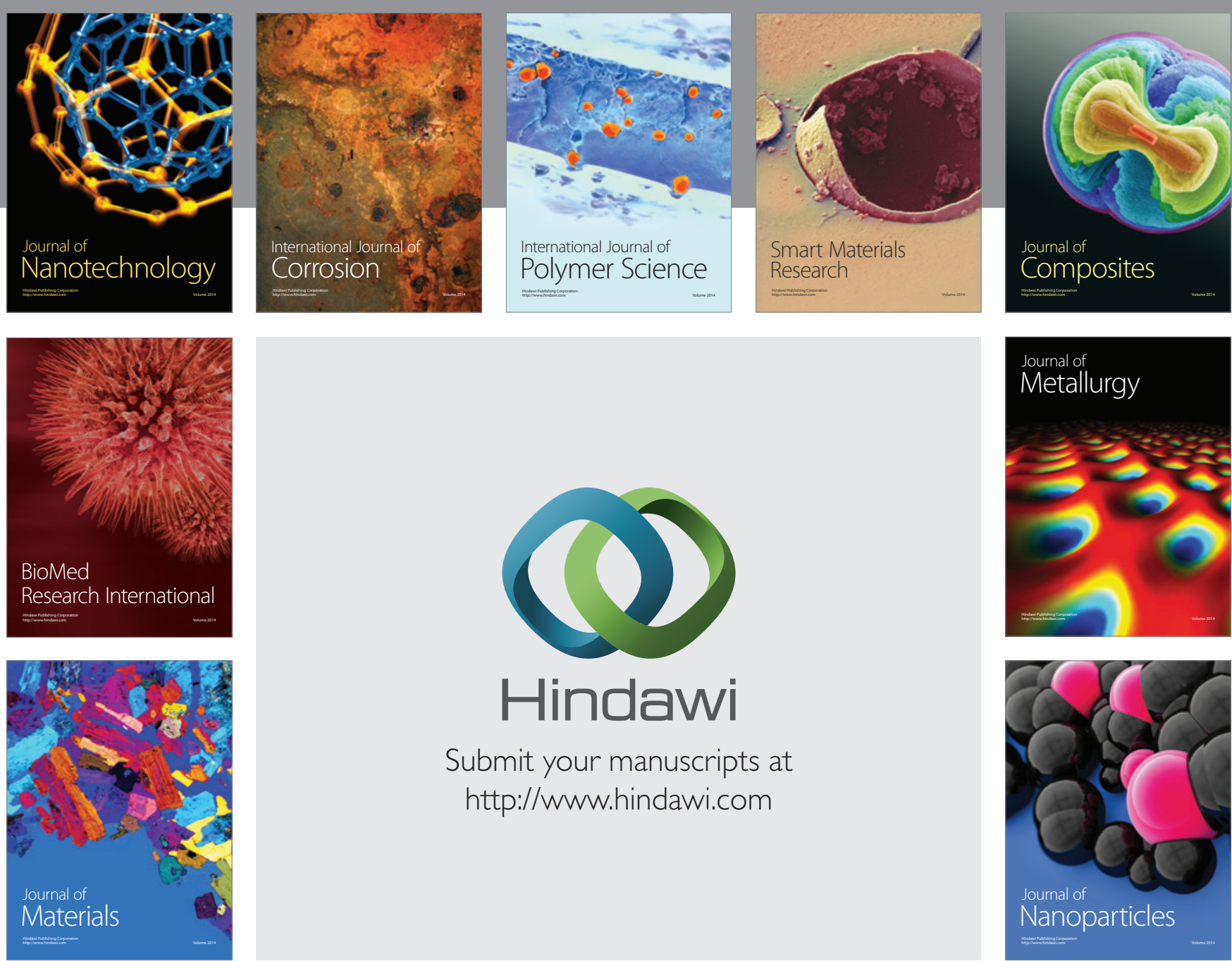

\section{Hindawi}

Submit your manuscripts at

http://www.hindawi.com

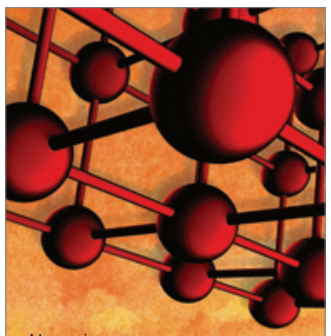

Materials Science and Engineering
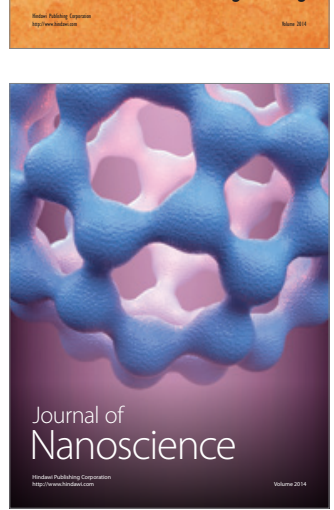
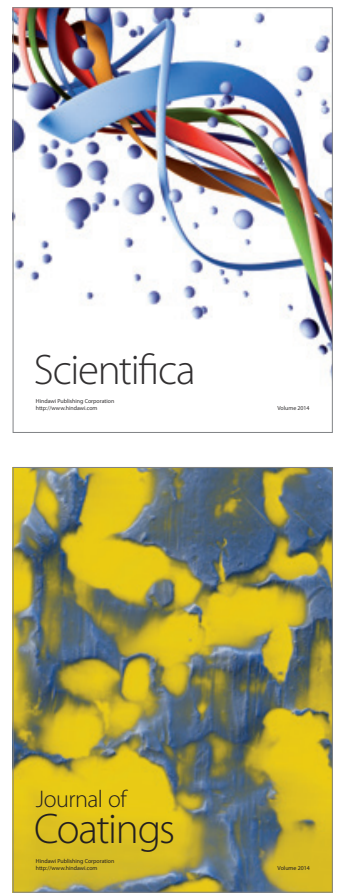
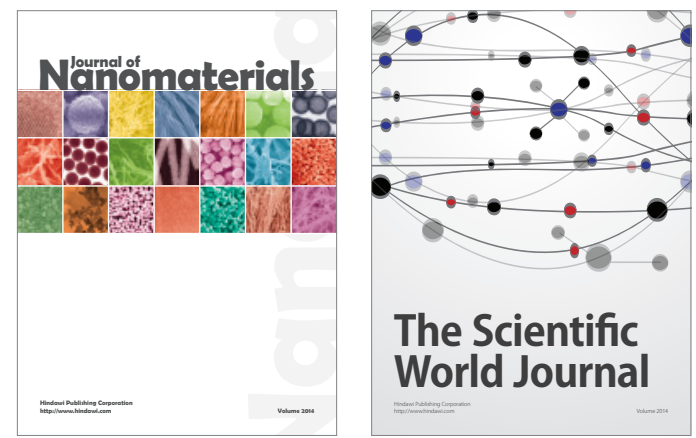

The Scientific World Journal
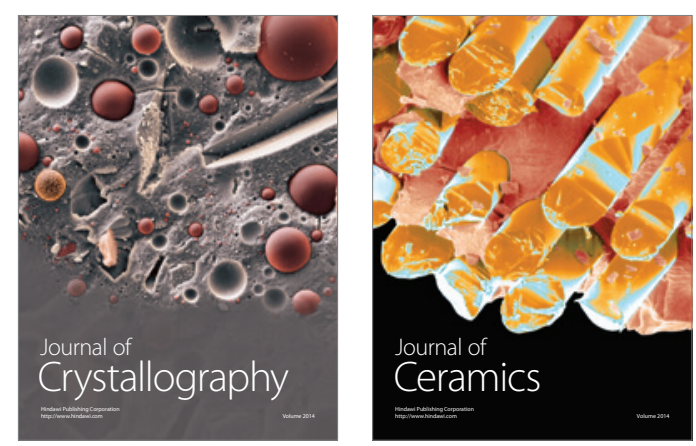
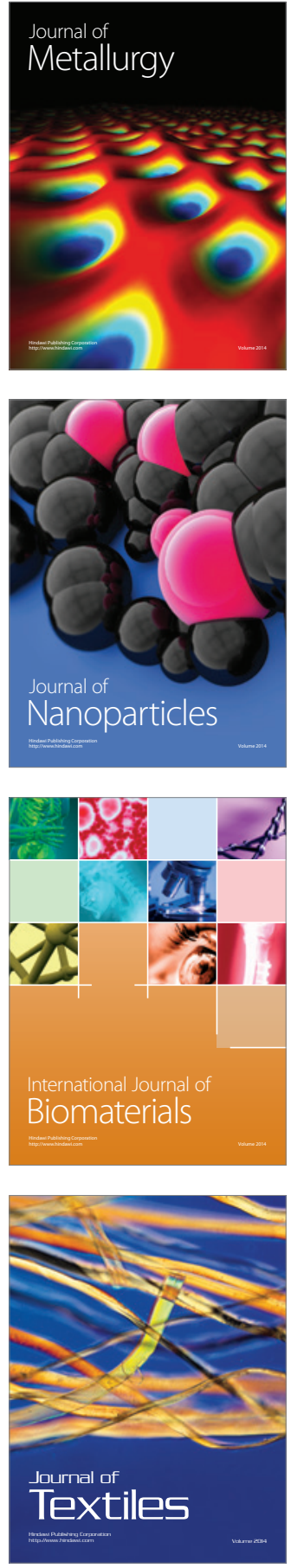